\section{FRI0502 IXEKIZUMAB REDUCES DISEASE ACTIVITY IN ACTIVE PSORIATIC ARTHRITIS PATIENTS WHO HAD PREVIOUS INADEQUATE RESPONSE TO TUMOUR NECROSIS FACTOR-INHIBITORS}

L.C. Coates ${ }^{1}$, P. Mease ${ }^{2}$, M.E. Husni ${ }^{3}$, E. Lespessailles 4,5 , D.H. Adams ${ }^{6}$, ${ }^{O}$. Benichou ${ }^{6}$, L. Kerr ${ }^{6}$, P. Helliwell ${ }^{1} .{ }^{1}$ University of Leeds, Leeds, United Kingdom; ${ }^{2}$ Swedish Medical Center and University of Washington, Seattle; ${ }^{3}$ Cleveland Clinic, Cleveland, United States; ${ }^{4}$ Orléans University; ${ }^{5}$ Department of Rheumatology, C.H.R. Orléans, Orléans, France; ${ }^{6}$ Eli Lilly and Company, Indianapolis, United States

Background: Psoriatic arthritis (PsA) is a chronic immune-mediated inflammatory disease associated with psoriasis, peripheral arthritis, enthesitis, dactylitis, and spondylitis. Ixekizumab (IXE), a monoclonal high affinity antibody that selectively targets interleukin-17A, has improved disease activity and physical function in bDMARD-naïve patients with active PsA. ${ }^{1}$ Herein, results are presented from a phase 3 trial (SPIRIT-P2; NCT02349295) with IXE in patients with active PsA and previous inadequate response to tumour necrosis factor-inhibitors (TNF-i).

Objectives: To explore the impact of IXE, as assessed by composite endpoints that incorporate multiple disease domains including peripheral arthritis, skin disease, enthesitis, dactylitis, spinal disease, functioning, and global disease assessment, up to 24 weeks (wks)

Methods: In this phase 3, multicentre, double-blind study, 363 adult patients with active PsA and a history of inadequate response to TNF-i were randomly assigned at a 1:1:1 ratio to subcutaneous administration of 80-mg IXE either every 4 wks (Q4W; $\mathrm{N}=122$ ) or every 2 wks (Q2W; $\mathrm{N}=123$ ) following a 160-mg starting dose at Wk 0 or placebo (PBO; $\mathrm{N}=118$ ). TNF-i inadequate response was defined as lack of efficacy to one or two TNF-i or intolerance to TNF-i. Response to treatment and disease activity were measured at Wks 12 and 24 by the following composite endpoints: minimal disease activity with skin component measured with the Psoriasis Area and Severity Index (MDA) or the static Physician Global Assessment of psoriasis (mMDA) and Composite Psoriatic Disease Activity Index (CPDAl) as well as traditional measures by Psoriatic Arthritis Response Criteria (PsARC). Treatment comparisons were made by a logistic regression model for categorical data with missing values imputed by nonresponder imputation (NRI); a mixed model for repeated measures analysis was used for continuous data. Results: At Wks 12 and 24, significantly more patients receiving IXEQ4W or IXEQ2W achieved MDA, mMDA, and PsARC compared with patients receiving PBO (Table). Results for MDA were similar to mMDA results within each treatment group at each time point. CPDAl total scores for patients receiving IXEQ4W or IXEQ2W were significantly improved compared with results for patients receiving $\mathrm{PBO}$

Table: Summary of Composite Endpoints at Weeks 12 and 24

\begin{tabular}{|c|c|c|c|c|c|}
\hline & & & PBO (N=118) & IXEQ4W (N=122) & IXEQ2W ( $N=123)$ \\
\hline \multirow[t]{2}{*}{ MDA } & Week 12 & $n(\%)$ & $6(5.1)$ & $31(25.4)^{k=x}$ & $21(17.1)^{* *}$ \\
\hline & Week 24 & $n(\%)$ & $4(3.4)$ & $34(27.9)^{2 * *}$ & $29(23.6)^{* * *}$ \\
\hline \multirow[t]{2}{*}{ mMDA } & Week 12 & $n(\%)$ & $6(5.1)$ & $31(25.4)^{\cdots \cdots}$ & $23(18.7)^{* *}$ \\
\hline & Week 24 & $n(\%)$ & $4(3.4)$ & $34(27.9)^{* * *}$ & $29(23.6)^{* \star * *}$ \\
\hline \multirow[t]{2}{*}{ PsARC } & Week 12 & $n(\%)$ & $28(23.7)$ & $61(50.0)^{* * *}$ & $64(52.0)^{* * *}$ \\
\hline & Week 24 & $n(\%)$ & $24(20.3)$ & $68(55.7)^{n \times n}$ & $58(47.2)^{n \times m}$ \\
\hline \multirow[t]{4}{*}{ CPDAI } & Week 12 & Change from baseline & $-0.9(0.4)$ & $-3.0(0.4)^{n \times n}$ & $-2.8(0.3)^{-3 . *}$ \\
\hline & & Effect Size & -- & $-2.1(-2.8$ to -1.5$)$ & $-1.9(-2.6$ to -1.3$)$ \\
\hline & Week 24 & Change from baseline & $-1.0(0.4)$ & $-3.7(0.4)^{* * *}$ & $-3.4(0.4)^{x+*}$ \\
\hline & & Effect Size & -- & $-2.7(-3.5$ to -2.0$)$ & $-2.4(-3.2$ to -1.7$)$ \\
\hline
\end{tabular}

Change from baseline is least square mean (SE); Effect size is least square mean difference versus PBO $(95 \% \mathrm{Cl}$ ).

" $p<01 ; \cdots " p<.001$.

Conclusions: Treatment with either IXEQ2W or IXEQ4W provides improvement in disease activity across multiple symptom domains, as measured by various composite endpoints, in patients with active PsA and who had a previous inadequate response to TNF-i.

References:

[1] Mease P et al. 2017 ARD 76(1):79.

Disclosure of Interest: L. Coates Grant/research support from: Abbvie, Janssen, Consultant for: Abbvie, Celgene, Janssen, Sun Pharma, Pfizer, UCB, MSD, Novartis, Eli Lilly and Company, P. Mease Grant/research support from: Abbvie, Amgen, Bristol Myers Squibb, Celgene, Crescendo, Genentech, Janssen, Eli Lilly and Company, Merck, Novartis, Phizer, UCB Pharma, Sun, Consultant for: Abbvie, Amgen, Bristol Myers Squibb, Celgene, Crescendo, Genentech, Janssen, Eli Lilly and Company, Merck, Novartis, Pfizer, UCB Pharma, Sun, Speakers bureau: Abbvie, Amgen, Bristol Myers Squibb, Celgene, Crescendo, Genentech, Janssen, Pfizer, UCB Pharma, M. Husni Consultant for: Eli Lilly and Company, Novartis, Abbvie, Celgene, Bristol Myers Squibb, Amgen, Janssen, and UCB phrama, E. Lespessailles Grant/research support from: Amgen and Eli Lilly and Company, Speakers bureau: Expancience, Novartis and Servier, D. Adams Shareholder of: Eli Lilly and Company, Employee of: Eli Lilly and Company, O. Benichou Shareholder of: Eli Lilly and Company, Employee of: Eli Lilly and Company, L. Kerr Shareholder of: Eli Lilly and Company, Employee of: Eli Lilly and Company, P. Helliwell Grant/research support from: AbbVie, Amgen, Bristol-Myers Squibb, Celgene, Eli Lilly and Company, Janssen, Merck, Novartis, and UCB
DOI: 10.1136/annrheumdis-2017-eular.2757

\section{FRI0503 VALIDATION OF NEW POTENTIAL TARGETS FOR REMISSION IN PSORIATIC ARTHRITIS IN PATIENTS TREATED WITH GOLIMUMAB}

L.C. Coates ${ }^{1}$, P. Rahman ${ }^{2}$, E. Psaradellis ${ }^{3}$, A. Karellis ${ }^{3}$, E. Rampakakis ${ }^{3}$ B. Osborne ${ }^{4}$, C. Tkaczyk ${ }^{4}$, A.J. Lehman ${ }^{4}$, F. Nantel ${ }^{4} .{ }^{1}$ Leeds University, Leeds, United Kingdom; ${ }^{2}$ Memorial University, St-Johns, NL; ${ }^{3}$ JSS Medical Research, Montreal, QC; ${ }^{4}$ Janssen Inc, Toronto, ON, Canada

Background: Treat to target recommendations in psoriatic arthritis (PsA) stated that the target of treatment should be remission or inactive disease. At that time, no definitions of remission or inactive disease existed and the only validated target available was the minimal disease activity (MDA) criteria. Since then, other potential targets have been developed including very low disease activity (VLDA) and the Disease Activity in PSA (DAPSA) score remission.

Objectives: Using an existing dataset allowing calculation of DAPSA and clinical cDAPSA scores and the VLDA criteria, the objectives were to calculate the proportion of patients achieving these criteria, their prognostic value and the overall patient impact of these disease states.

Methods: BioTRAC is an ongoing, prospective registry of inflammatory arthritis patients initiating treatment with infliximab, golimumab (GLM) or ustekinumab. PsA patients treated with GLM were included. Data collected at baseline, 6 and 12 months (mts) were used. DAPSA remission was defined as: TJC + SJC + $\mathrm{PtGA}+\mathrm{Pt}$ pain $+\mathrm{CRP} \leq 4$. cDAPSA Remission was defined as: TJC + SJC + PtGA + Pt pain $\leq 4$. Very low disease activity (VLDA) was achieved when all 7 MDA criteria were satisfied: TJC28 $\leq 1, \mathrm{SJC} 28 \leq 1$, PASI $\leq 1$, Pain (VAS) $\leq 15 \mathrm{~mm}$, PtGA (VAS) $\leq 20 \mathrm{~mm}, \mathrm{HAQ} \leq 0.5$ and tender entheseal points $\leq 1$. Correlation between DAPSA, cDAPSA and VLDA were based on tetrachoric analysis.

Results: A total of 188 patients $(53.2 \%$ female gender) were included with a mean (SD) disease duration of 5.46 (6.91) years. DAPSA remission was achieved in $5.1 \%, 24.2 \%$ and $30.0 \%$ of patients at baseline, $6 \mathrm{mts}$ and $12 \mathrm{mts}$, respectively. Those patients had a significant reduction in the number of TJC, SJC, enthesitis and dactylitis $(p<0.043)$. cDAPSA remission was achieved in $5.2 \%, 33.1 \%$ and $38.3 \%$ of patients at baseline, $6 \mathrm{mts}$ and $12 \mathrm{mts}$, respectively. Those patients had a significant reduction in the number of TJC, SJC and enthesitis only $(p<0.002)$. VLDA was achieved in $2.1 \%, 17.2 \%$ and $15.6 \%$ of patients at baseline, $6 \mathrm{mts}$ and $12 \mathrm{mts}$, respectively and those patients had a significant reduction in the number of TJC, SJC, enthesitis and PASI $(p<0.002)$. The overall correlation for DAPSA or cDAPSA remission vs. VLDA achievement were both at 0.999 (Asymptotic Standard Error $<0.027$ ) although this is likely driven by the high number of patients who are not in either state. $75 \%$ and $53.3 \%$ of patients in DAPSA and cDAPSA remission, respectively, also achieved VLDA $(p<0.001)$. In contrast, patients who did not achieve neither CDAPSA nor DAPSA never achieved VLDA. Nonetheless, patients in remission had significantly greater HAQ scores $(p<0.03)$ if they had remaining dactylitis or active skin disease (BSA $\leq 10 \%$; cDAPSA only).

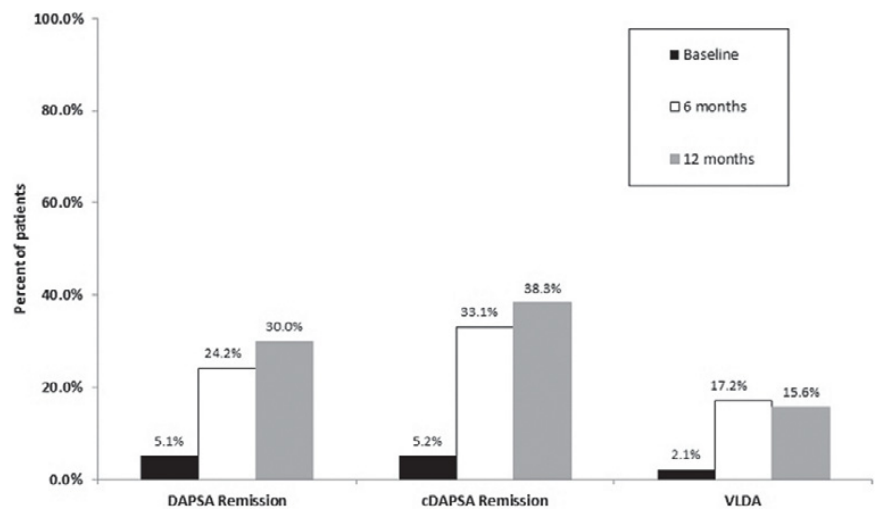

Conclusions: DAPSA, cDAPSA and VLDA represent new potential target for remission in PSA with VLDA being the most stringent criteria. There was a high level of correlation between these scores although residual activity in dactylitis and skin despite DAPSA remission has some impact on patients' function.

Disclosure of Interest: L. Coates Grant/research support from: Abbvie, BMS, Celgene, Janssen, Lilly, MSD, Novartis, Pfizer, Sun Pharma, UCB, Consultant for: Abbvie, BMS, Celgene, Janssen, Lilly, MSD, Novartis, Pfizer, Sun Pharma, UCB, P. Rahman Consultant for: Abbott, AbbVie, Amgen, BMS, Celgene, Janssen, Novartis, Pfizer, Roche, E. Psaradellis Employee of: JSS Medical Research, A. Karellis Employee of: JSS Medical Research, E. Rampakakis Employee of: JSS Medical Research, B. Osborne Employee of: Janssen, C. Tkaczyk Employee of: Janssen, A. Lehman Employee of: Janssen, F. Nantel Shareholder of: Jonhson and Johnson, Employee of: Janssen

DOI: 10.1136/annrheumdis-2017-eular.3855 